\title{
ТЕНДЕНЦИИ ИЗМЕНЕНИЙ БУХГАЛТЕРСКОЙ ОТЧЕТНОСТИ В ПЕРИОД ПАНДЕМИИ
}

\section{(C) 2021 Шлычков Дмитрий Сергеевич}

кандидат экономических наук, доцент, доцент департамента аудита и корпоративной отчетности Финансовый университет при Правительстве Российской Федерации, Россия, Москва

E-mail: sds457@mail.ru

\section{(c) 2021 Корзун Илья Александрович}

студент факультета экономики и бизнеса, департамента корпоративных финансов и бизнес-аналитики Финансовый университет при Правительстве Российской Федерации, Россия, Москва

E- mail: Nuzrokeli@gmail.ru

\section{(c) 2021 Урусова Елизавета Олеговна}

студент факультета экономики и бизнеса, департамента корпоративных финансов и бизнес-аналитики Финансовый университет при Правительстве Российской Федерации, Россия, Москва E- mail: liz.urusova02@mail.ru

В настоящей статье рассматриваются финансовые кризисы банковского сектора, изменение бухгалтерской (финансовой) отчетности компаний, а также взаимосвязь банковского сектора с экономикой. Влияние пандемии Covid-19 на бухгалтерскую (финансовую) отчетность банков, ее изменение. Выявление существующих тенденций и выявление новых путей роста.

Ключевые слова: бухгалтерская (финансовая отчетность), банковский сектор, финансовый кризис, ликвидность, отчет о финансовых результатах, мультипликаторы, тенденции, финансовые обязательства.

Актуальность изменения бухгалтерской отчетности всегда носит сравнительный анализ. Сравнительный анализ позволяет оценить управленческие решения прошлого, понять тенденцию развития компании, проанализировать развитие компании на протяжении определенного срока, а также тенденции всей отрасли в целом. Важно понимать, что каждый финансовый отчет компании носит не только финансовый и результативный характер, а также исторический и предикативный. Сфера банковского сектора уже существует в нашем мире более 200 лет и за этот промежуток времени немало раз оказывалась в кризисных и предкризисных ситуациях. Нетрудно вспомнить, что за последние десятилетия в мире произошло десятки подобных ситуаций и от большинства кризисов экономика стран смогла оправиться. На функционирование банковской сферы влияют не только внутренние факторы и действия, принимаемые регулятором, но и внешние, например, современная политическая ситуация в мире, или природные катаклизмы. На сегодняшний день, пандемия
COVID-19, привнесла большие изменения во всем мире, а в частности и в банковскую сферу. Поскольку, банковский сектор надежно укреплен в современной экономике любого государства и любые дисфункции данной отрасли сказываются на всех остальных сферах экономики страны, а в первую очередь, на населении данной страны.

Немаловажным является тот факт, что только от сферы банковских услуг, прибыль банков сравнительно мала, что побуждает банков внедрятся во все доступные для них отрасли, для увеличения маржинальности своего бизнеса.

Аналитическому исследованию подверглась финансовая отчетность банковского сектора на примере: ПАО «Сбербанк России» и АО «Тинькофф банк». Выбор банков был обусловлен их различием в формате оказания услуг, инвестиционному доверию со стороны пользователей, а также наличием участия государства в управлении данными банками.

Бухгалтерская (финансовая) отчетность, является ключевым показателем оценки продук- 
тивности и рентабельности компании. Именно с помощью данных отчетов возможно проанализировать как внешние или внутренние факторы на рынке, влияют на саму компанию, а главное, какие действия она предпринимает с целью формирования стабильности и подстройки под постоянно изменяющиеся условия рынка.

В рамках данного исследования использовался комплекс методов: системный подход, исторический подход, описательный анализ, сравнительный анализ, исторический, экономико-математический анализ, статистический анализ. В данной работе был проведен анализ нормативно-правовых актов и документов различных государственных органов, а также аналитические отчеты консалтинговый и аудиторских агентств. В работе представлены расчеты, графики, таблицы и диаграммы по исследуемой теме, способствующие пониманию развивающихся тенденций в бухгалтерской (финансовой) отчетности данных банков.

Анализ финансовых отчетов в данном исследовании, в первую очередь, опирается на методикотеоретическую базу, а также на изучение отчетов таких аналитических агентств, как Deloitte, KPMG, McKinsey\&Co и др. Возможные тенденции развития банковского сектора, основаны на работах выдающихся авторов: Горловой Д.Н. [9], Дицуленко О.И. [10], Балюк И.А. [11] и др.

Банковский сектор положил свое начало еще в 1817 году и за сравнительно длительный промежуток времени претерпел множество изменений и кризисов. Появление интернета, а как следствие, введение кредитных карт и безналичных денег, крайне сильно развили и простимулировали данную сферу. Но и за каждым успехом и развитием, следует спад, следует рассмотреть некоторые из них. К самым популярным следует отнести ипотечный кризис 2008 года в США. Но сам кризис начал проявляться уже в 2006 году, а уже в 2007, о нем знало большинство финансовых и инвестиционных аналитиков. В результате, которого, в большинстве своем, пострадало население. По подсчетам аналитиков только различных финансовых организаций составили более 4 триллионов долларов*. Расходы государства на восстановление по]страдавшего сектора и экономики в целом, составили более 7 триллионов долларов США **. Но любой банковский кризис связан не только с невыплатой сумм или обесцениванию валюты, с банками взаимодействуют почти все отрасли экономики, в той или иной степени.

Например, вследствие вышеупомянутого нами ипотечного кризиса в США, банки перестали выдавать ссуды на покупку автомобилей, что негативно повлияло на автопроизводителей и впоследствии создало автомобильный кризис. Но также нельзя не брать во внимание тесную взаимосвязь финансов и политики, так как данный кризис был не только крахом финансовой системы США, но и снизил геополитическую роль США на мировой арене. Конечно, не стоит и говорить о финансовой отчетности множества организаций, которые обанкротились, но рассмотрим, к примеру, отчетность General Motors, одну из самых популярных фирм-автопроизводителей в США.

Исходя из представленной таблицы на рисунке 1 , следует очевидный вывод, по результатам 2008 года, все показатели компании упали более чем в 2 раза, а количество рыночных ценных бумаг, более чем в 160 раз, и как мы видим, тенденция к улучшению ситуации с акциями не получила стремительного роста. По результатам 2007 года, убыток акционерного капитала вырос более чем в 2 раза, но финансовая помощь Правительства США, способствовала нормализации ситуации на рынке.

Стоит учитывать тот факт, что США, на тот ** «Американский ипотечный кризис: предпосылки, причины, опыт для России» В.Н. ПОПОВ, А. А. ОРЕШКОВ

\begin{tabular}{|c|c|c|c|c|c|}
\hline $\begin{array}{l}\text { "Балансовые отчеты GM } \\
\text { (Годовой GA.АР в миллионах долларов) " }\end{array}$ & (FY 2009) & (FY 2008) & (FY 2007) & (FY 2006) & (FY 2005) \\
\hline Денежные средства и их эквиваленты & (Dec. 30. 2009) & (Dec. 30.2008 & (Dec. 30. 2007) & (Dec. 30. 2006) & (Dec. 30. 2005) \\
\hline Денежные средства и инвестиции с ограничением использования, текущие, всего & - & 100.00 & 268.00 & 349.00 & $15,539.00$ \\
\hline Ценные бумаги, имеюшиеся в наличии для продажи, долговые ценные бумаги, текущая стоимость & - & 128.00 & 215.00 & 188.00 & $18,310.00$ \\
\hline Рыночные ценные бумаги & 134.00 & 13.00 & $2,139.00$ & 138.00 & $1,416.00$ \\
\hline Денежные средства с ограничением & $13,917.00$ & - & - & - & - \\
\hline Всего инвестиций & $14,051.00$ & 141.00 & $2,354.00$ & 326.00 & $19,726.00$ \\
\hline Неконтролируюшие интересы и прочее & $7,706.00$ & 814.00 & $1,614.00$ & $1,190.00$ & $1,047.00$ \\
\hline Итого акционерный капитал & $21,249.00$ & $-86,154.00$ & $-37,094.00$ & $-5,441.00$ & $14,653.00$ \\
\hline
\end{tabular}

Puc. 1. Годовая отчетность General Motors за 2005-2009 года

Годовая отчетность General Motors [Электронный ресурс]. URL: https://csimarket.com/stocks/balance. php?code=GM\&annual\&hist=11 (дата обращения: 05.12.2021). 
момент, являлось эмитентом самой стабильной валюты в мире, восстановить ситуацию было сравнительно легче, чем, например, в Российской Федерации. Но стоит и упомянуть, что данный кризис имел мировой характер и сильно повлиял на страны, зависящие от США, в том числе это и сказалось на Россию.

Во-первых, снизилась цена на нефть, (в июне 2008 г. баррель марки Brent стоил выше 140 долл. США, а в декабре снизился до 40 долл. США)*, а поскольку бюджет России уже десятилетиями основан на экспорте ГСМ, это привело к снижению профицита страны и в следствии, к уменьшению золотовалютного резерва.

Во-вторых, анализируя график на рисунке 2 , очевидно, что в результате понижения цены на нефть, произошел и обвал российского фондового рынка. По оценкам аналитиков, он потерял примерно $2 / 3$ своей стоимости.

B-третьих, уменьшение инвестиций из-за рубежа, которых на тот момент было крайне мало, а в 2009 году и вовсе начался отток иностранных денежных средств, который и на данный момент трудно восполним.

Проанализировав прошлое банковской сферы, ее влияния на экономику и результаты кризисов, следует перейти к самому значимому происшествию в мире, за последние 5 лет. Пан- демия Covid -19 внесла существенные изменения в экономики разных стран и проверяла их на прочность. К одному из главных показателей банковского сектора, на наш взгляд, стоит относить прибыль. За апрель 2020 г. чистая прибыль банковского сектора составила около 32 млрд. руб.**, что значительно ниже результатов предыдущих месяцев этого года, а положительный результат показали всего 246 банков, что составляет примерно 63\% от общего количества банков, действовавших на 01.03.2020.

Исходя из рисунка 3, наблюдается резкий спад в темпе роста средств юридических лиц, что обусловлено тотальным локдауном. Темп роста упал более чем на $4 \%$ и приобрел отрицательное значение. В отчетах следующих месяцев, темп роста приобрел положительное значение и почти вернулся к допандемийному уровню. Но нельзя не отметить то, что пандемия в нашей стране носит циклический характер и в отчете ЦБ РФ за апрель 2021 года наблюдается незначительный подъем в данном критерии. Чистая прибыль банковского сектора увеличилась более чем в 7 , но количество прибыльных банков снизилось до 221 банка.

Бухгалтерская (финансовая) отчетность тоже существенно изменилась за данный промежуток времени [1]. Существенной проблемой было

\footnotetext{
* Агентство экономической информации [Электронный ресурc]. URL: «Прайм» https://1prime.ru/ sience/20190402/829858467.html (дата обращения: 05.12.2021).

** Информационно - аналитический материал Центрального Банка РФ «О развитии банковского сектора в Российской федерации в апреле 2020 года [Электронный ресурс]. URL: https://www.cbr.ru/Collection/Collection/ File/27900/razv_bs_20_04.pdf (дата обращения: 08.12.2021).
}

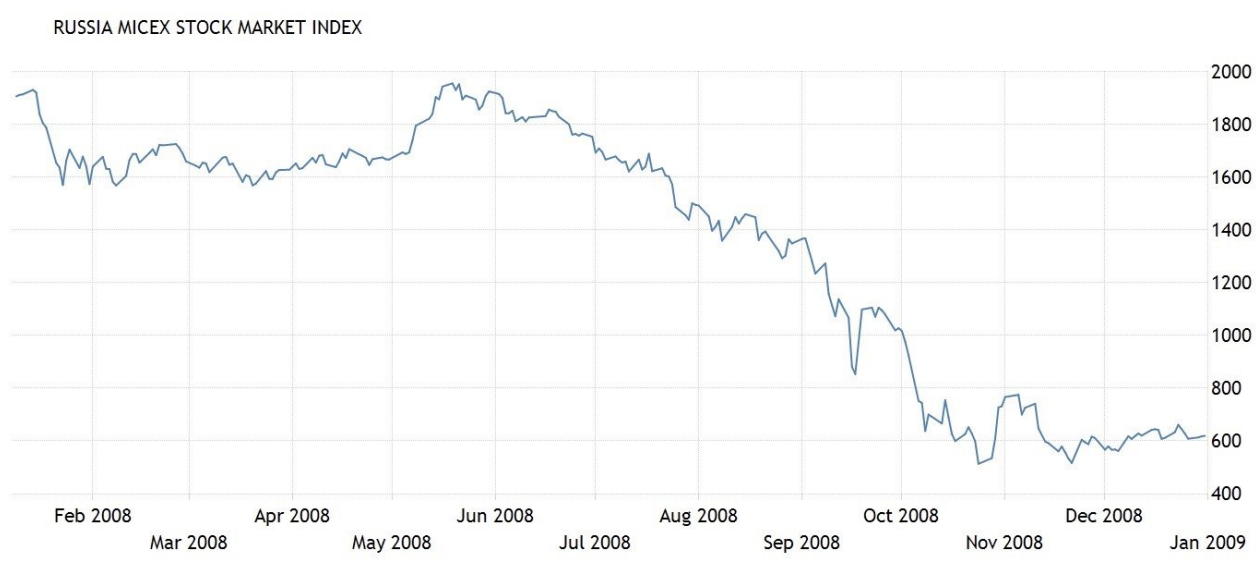

Puc. 2. Динамика индекса ММВБ в 2008 году

Динамика индексов Московской биржи [Электронный ресурс]. URL: https://www.moex.com/ru/index/idxgraph. aspx (дата обращения: 07.12.2021). 


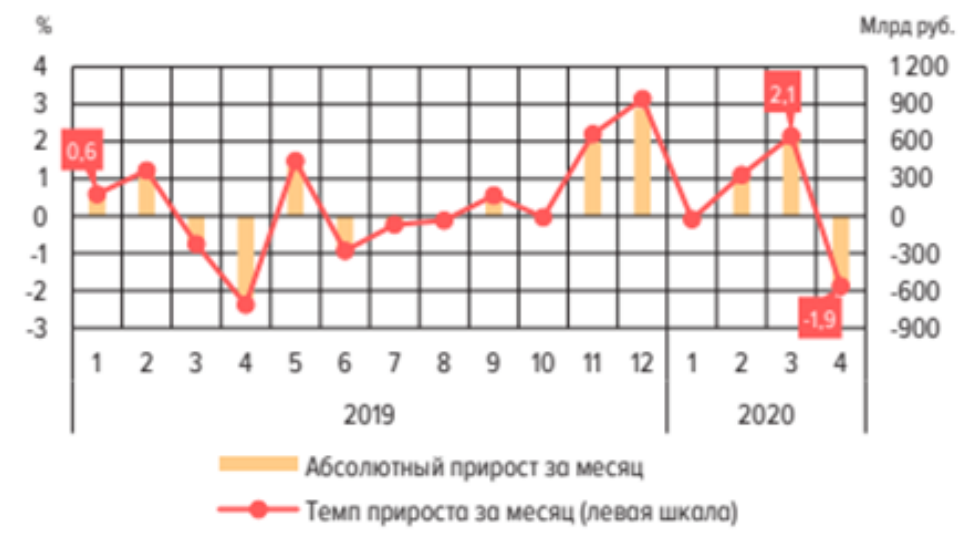

Источник: формо отчетности 0409101.

Puc. 3. Динамика средств юридических лиц за апрель 2020г.

Информационно - аналитический материал Центрального Банка РФ «О развитии банковского сектора в Российской федерации в апреле 2020 года [Электронный ресурc]. URL: https://www.cbr.ru/Collection/Collection/ File/32321/razv_bs_21_04.pdf (дата обращения: 08.12.2021).

первое полугодие, с появления коронавируса, поскольку многие регионы не классифицировали пандемию как обстоятельство непреодолимой силы, а лишь некоторые субъекты. Из-за тотального локдауна были сорваны сроки поставок и оказания различных услуг, как следствие этого, начисление пени, штрафов и расчета упущенной выгоды. С течением времени, активы организаций начали стабилизироваться, не только в связи с окончанием самоизоляции, но и с появлением рекомендаций по расчету между организациями со стороны регулятора.

Стоит отметить, что Правительство РФ предоставляло налоговую отсрочку* компаниям, для стабилизации их состояния и избегания еще больших убытков, но в условиях полного локдауна, данная поддержка не оказала столь значительный эффект.

Рабочие ресурсы были переведены на удаленную форму, со снижением заработной платы или увольнением, для последующей организацией кабинета самозанятого, все это было предпринято для минимизации издержек со стороны работодателя.

Очевидно, что бухгалтерская (финансовая) отчетность зависит от локдауна и мер, предпринимаемых Правительством страны, но нельзя отрицать одно - запас финансовой прочности большинства организаций, а также банков значительно уменьшился, сравнительно с 2019 годом и по оценкам аналитиков сможет вернуться на этот уровень, спустя 3-5 лет.

В результате пандемии, на территории РФ осталось около 5,6 млн. малых и средних предприятий. Более 1 млн. предприятий закрылось за первый год. Исходя из данных, становится очевидно, что пандемия оказала не только отрицательный эффект на экономику страны, но и на финансовую составляющую данных компаний, а главное - на благосостояние населения.

Для более детального и обоснованного анализа, были проанализированы различные финансовые отчеты компаний, из разных отраслей и сгруппировали их в соответствии с тем, какое влияние пандемия оказала на их доходы от операционной деятельности:

1. Отрасли, наиболее пострадавшие от Covid-19. Исходя из данных, полученных нами в результате анализа можно сказать, что к этим отраслям относится сфера туризма и сфера общественного питания **.

2. Отрасли, на развитие которых пандемия повлияла положительно. Например, сфера онлайн-кинотеатров, сфера доставки питания,

\footnotetext{
* Поддержка МСП в контексте COVID-19 [Электронный ресурс]. URL: https://ach.gov.ru/upload/pdf/Covid-19-SME. pdf (дата обращения 14.12.2021)

** Перечень отраслей российской экономики, в наибольшей степени пострадавших в условиях ухудшения ситуации в результате распространения новой коронавирусной инфекции [Электронный ресурc]. URL: https://www. economy.gov.ru/material/dokumenty/perechen_otrasley_ekonomiki_postradavshih_v_rezultate_rasprostraneniya_ koronavirusnoy_infekcii.html (дата обращения: 08.12.2021).
} 
которые уже до этого работали онлайн, и пандемия позволила расширить свою аудиторию и намного увеличить доходы, прикладывая к этому меньше усилий, чем если это было бы без появления «черного лебедя».

3. Отрасли, влияние на которые так явно не просматриваются, например, сфера банкинга и финансов.

Детально был проанализирован финансовый и банковский сектор, поскольку он является цикличным. Когда COVID-19 появился, мировая экономика уже показывала небольшие темпы замедления*, а пандемия только ухудшила ситуацию. В условиях потрясений компании испытывали затруднения, а Центральный Банк России, как и другие центральные банки, активно вмешивался в экономику с целью успокоить её и сделать более стабильной.

Для анализа были выбраны две компании из отрасли банковского сектора экономики, которые изначально имели более устойчивое положение на рынке с наибольшей капитализацией, и которые также располагаются на первом уровня листинга ПАО «Московская биржа». Это ПАО «Сбербанк России» и АО «Тинькофф Банк». Необходимо отметить, что для включения в этот котировальный список компания должна раскрывать внутреннюю информацию качественно. Кроме того, немаловажный фактор - это участие государства в их деятельности.

Их описание представлено ниже:

1. ПАО «Сбербанк России» - банк России с наибольшей капитализацией в отрасли (7368 315 руб.), предоставляющий полный спектр услуг, осуществляющий свою деятельность не только в России, но и в странах Восточной и Западной Европы. Основным акционером является Министерство Финансов РФ (50\% + 1 акция). Деятельность банка осуществляется в трех главных направлениях: корпоративный банкинг, розничный бизнес, инвестиционный банкинг. Для компании важно качественно обслуживать клиентов, технологически быстро развиваться.
2. АО «Тинькофф Банк» - банк, предоставляющий розничные финансовые услуги онлайн. Основная деятельность компании: розничный банкинг, услуги счетов IE и SME, стразовые операции и услуги MVNO. Капитализация на момент анализа рынка составляет 1380911 руб.

Были изучены обязательные нормативы Банка России **, это количественные показатели деятельности, которые обязаны соблюдать банки. Оба этих банка являются системно значимыми, следовательно, к ним предъявляются более высокие требования. Тинькофф был включен в данную категорию только в 2021 году***, это может служить показателем того, что пандемия не только не ухудшила позицию банка на рынке, но и улучшила её.

Рассмотрим нормативы ликвидности, чтобы более полно сформировать представление об устойчивости банков. Первым для рассмотрения будет ПАО «Сбербанк России» (Таблица 1 ).

После анализа нормативов ликвидности становится понятно, что компания с запасом покрывает все необходимые значения, но после пандемии произошли достаточно серьезные колебания, особенно в разрезе текущей ликвидности банка, потому значение на 01.01.21 составило всего 55\% от значений предыдущего периода, это означает, что компания в разрезе одного месяца была менее устойчива, чем в периоды до этого [2].

Данный показатель еще не дошел до тех показателей, которые были до пандемии, а темпы роста достаточно низкие. Также достаточно сильно снизилось значение мгновенной ликвидности, который определяет риск платежеспособности в течение одного дня. Конечно, «Сбербанк России» имеет высокие показатели, но можно заметить, что пандемия достаточно сильно повлияла на его ликвидность, хотя нормативные значения все равно остались высокими.

Для начала рассмотрим бухгалтерский баланс двух организаций, начнем с ПАО «Сбербанк России» (Рисунок 4).

\footnotetext{
* Аналитическая статья Deloitte: «Возможные последствия COVID-19 для банковского сектора и сектора рынков капитала» [Электронный ресурс]. URL: https://www2.deloitte.com/us/en/insights/economy/covid-19/bankingand-capital-markets-impact-covid-19.html?id=us:2em:3na:4di6693:5awa:6di: MMDDYY:\&pkid=1007068\#endnote-2 (дата обращения: 08.11.2021)

** Инструкция Банка России от 29.11.2019 N 199-И «Об обязательных нормативах и надбавках к нормативам достаточности капитала банков с универсальной лицензией» [Электронный ресурс] // СПС КонсультантПлюс (дата обращения: 08.11.2021)

*** Статья TACC «ЦБ включил «Тинькофф» в список системно значимых банков» [Электронный pecypc]. URL: https://tass.ru/ekonomika/12629321 (дата обращения: 08.11.2021)
} 
Таблица 1. Ликвидность ПАО «Сбербанк России»

\begin{tabular}{|c|c|c|c|c|c|c|}
\hline \multirow{2}{*}{$\begin{array}{l}\text { Норматив } \\
\text { ликвидности }\end{array}$} & \multirow{2}{*}{$\begin{array}{l}\text { Нормативное значе- } \\
\text { ние, установленное } \\
\text { Банком России,\% }\end{array}$} & \multicolumn{5}{|c|}{ Нормативное значение на отчетную дату,\% } \\
\hline & & На 01.10 .21 & На 01.01.21 & На 01.01.20 & На 01.01.19 & На 01.01 .18 \\
\hline $\begin{array}{l}\text { Норматив мгновен- } \\
\text { ной ликвидности } \\
\text { банка (Н2) }\end{array}$ & Минимум 15 & 135.4 & 98.5 & 161.9 & 185.8 & 161.1 \\
\hline $\begin{array}{l}\text { Норматив текущей } \\
\text { ликвидности банка } \\
\text { (H3) }\end{array}$ & Минимум 50 & 139.0 & 127.7 & 229.2 & 232.1 & 263.8 \\
\hline $\begin{array}{l}\text { Норматив долгосроч- } \\
\text { ной ликвидности } \\
\text { банка (H4) }\end{array}$ & Максимум 120 & 64.4 & 65.3 & 57.1 & 64.0 & 57.6 \\
\hline
\end{tabular}

Отчеты ПАО «Сбербанк» за 2018-2021 год.

https://www.sberbank.com/common/img/uploaded/files/info/806-011121.pdf

https://www.sberbank.com/common/img/uploaded/files/info/uos_ori_01012020.pdf

https:/www.sberbank.com/common/img/uploaded/files/info/img-129163755-0001.pdf

https://www.sberbank.com/common/img/uploaded/files/info/img-129141059-0001.pdf

https://www.sberbank.com/common/img/uploaded/files/info/img-129141059-0001.pdf

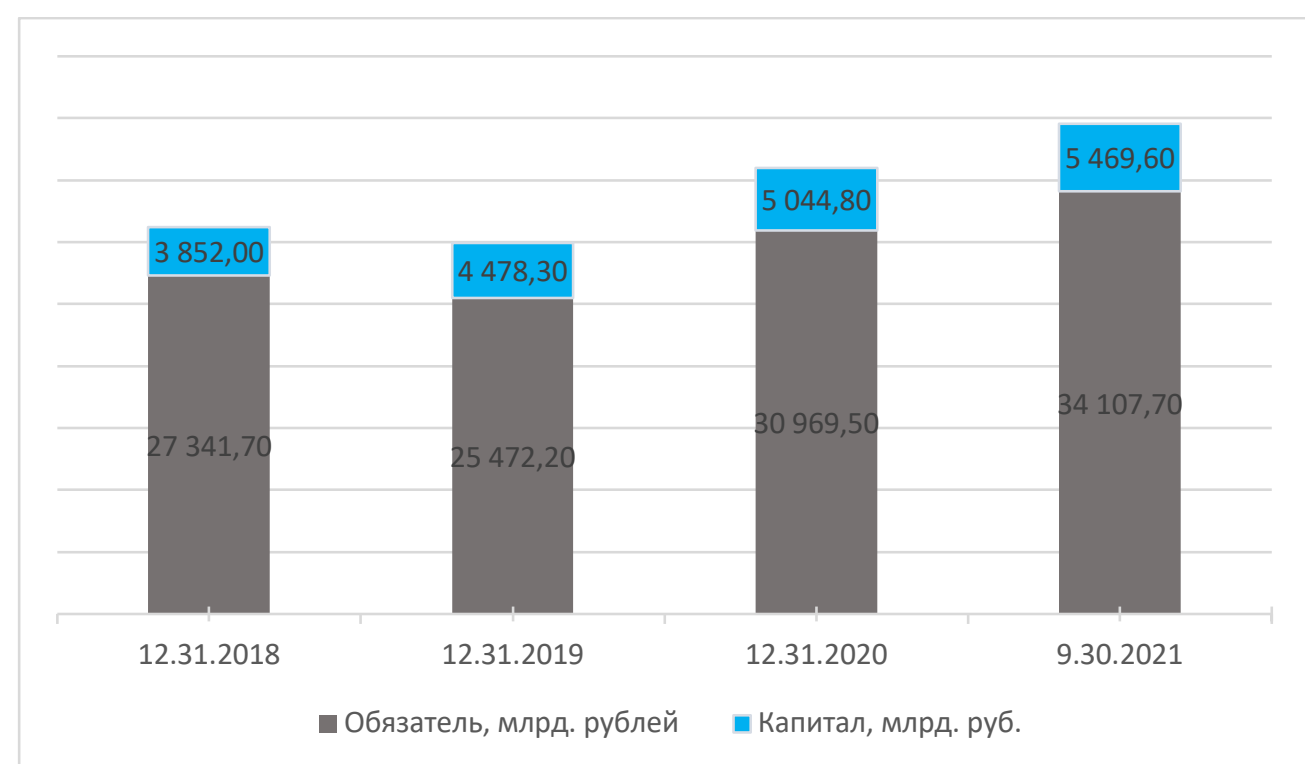

Puc. 4. Капитал и обязательства компании «Сбербанк»

(составлено автором на основе данных годовых и поквартальных отчетов)

Сведения из годовых отчетов ПАО «Сбербанк» за 2018-2021 гг.

https://www.sberbank.com/common/img/uploaded/files/info/ifrs2021/3q_oct/finstate/3q2021_ifrs_ ru_281021public3q_ru.pdf

https://www.sberbank.com/common/img/uploaded/files/info/ifrs2020/04/ifrs_4q_public_all2020_0403ru.pdf https://www.sberbank.ru/common/img/uploaded/files/info/ifrs2019/sberbank_ifrs_ye2019_rus.pdf?_ ga=2.248863495.181837809.1639398822-1348109431.1631254696

https:/www.sberbank.com/common/img/uploaded/files/info/ifrs2018/__sberbank_ifrs-ye2018-rus_.pdf 
Как мы видим из представленной диаграммы, обязательства компании растут, но в 2019 количество обязательств снизилось, самый большой скачок произошел после пандемии, данный показатель увеличился на 21\%, что указывает на достаточно быстрый рост, произошедший из-за изменения конъюнктуры рынка банковских услуг, в том числе из-за того, что ПАО «Сбербанк России» в 2020 году выдал кредитов розничный потребителям на $17 \%$ больше, чем в предыдущий период, и на 9\% в корпоративном секторе.

Такими действия компания поддерживала российскую экономику в период пандемии и увеличение количества выданных кредитов связано с тем, что ЦБ в этот период постепенно снижал кредитную ставку, делая эту услугу более доступной для потребителей*, тем самым повышая покупательную способность населения. Также активы компании увеличились на 7,1\% за счет роста кредитного портфеля и изменения макронадбавок по розничным кредитам. Изучая отчет о движении денежных средств, мы заметили, что в 4,3 раза увеличился поток денежных средств за счет прироста в разрезе корпоративных клиентов. Также увеличился поток денежных средств, использованных в финансовой деятельности, количество дивидендов, уплаченных за 9 месяцев 2020 года в 256 раз меньше, чем дивиденды, уплаченные за 9 месяцев 2021 года.

Далее был проанализирован отчет о финансовых результатах, из которого можно сделать выводы, что:

- За 2020 год компания получила прибыль в размере 760,3 млрд. руб., но за 9 месяцев 2021 года компания заработала 978,1 млрд. руб., что на 16\% больше, чем чистая прибыль в 2019 году, которая составляла 845,0 млрд. руб., и почти на 30\% больше, чем прибыль за 2019 год. В 2018 году компания заработала 831,7 млрд. руб. Из этих данных можно сделать вывод, что динамика роста прибыли увеличилась в период после пандемии, до этого она составляла 5-10\%, то теперь чистая прибыль увеличилась почти на 20\%, если сравнивать с 2019 и 2020 годом.

- Операционные расходы компании увеличились на 10,9\% по сравнению с предыдущим периодом и составили 485,1 млрд. руб. Отношение между доходами и расходами состави- ло 27,9\%, в 2020 году отношение было 29,7\%, а в 2019 24,5\%. Эти изменения можно связать с тем, что пандемия заставила компании развиваться быстрее в цифровой среде, а также максимально снижать затраты, используя новые технологии.

В процессе анализа отчета о финансовых результатах были рассмотрены тенденции внутри банковской сферы, которые определяют развитие ПАО «Сбербанк», сейчас банки инвестируют в те технологии, которые позволяют сократить расходы, оптимизировать процессы и повысить эффективность работы в условиях дистанционного формата.

Следующим этапом исследования был анализ отчетности АО «Тинькофф Банк», его можно отнести к необанкам**, которые осуществляют свою деятельность только онлайн. Именно это, по нашему мнению, позволило компании в 2021 году стать системно значимым банком, потому что к этому моменту у банка уже была база, на которой они смогли работать в период пандемии, так как не было необходимости сильно изменять внутренние процессы, чтобы предлагать своим потребителям услуги. АО «Тинькофф Банк» может составить конкуренцию ПАО «Сбербанк», поскольку тенденции в современной банковской сфере во всем мире такова, что сейчас активно увеличивают свою клиентскую базу не классические банки, а банки, которые являются более гибкими, которые могут обеспечить персонализированный подход в условиях диджитализации пространства [3].

Первичным показателем, который необходимо рассмотреть, являются нормативы ликвидности, в особенности из-за того, что АО «Тинькофф Банк» стал системно-значимым только в 2021 году, следовательно, можно предположить, что его ликвидность повысилась, он стал более устойчивым и в его деятельности не произошло сильных негативных изменений изза пандемии [4], что отражено в Таблице 2.

После анализа нормативов ликвидности становится понятно, что компания покрывает все необходимые значения, и в период пандемии просадка оказалось минимальной. По сравнению с ликвидностью ПАО «Сбербанк», данные мгновенной ликвидности значительно ниже,

* Статья ЦБ РФ [Электронный ресурс]. URL: https://www.cbr.ru/press/pr/?file=24072020_133000Key.htm (дата обращения: 08.12.2021)

** Отчет KPMG «Будущее Розничных банковских услуг» [Электронный ресурс]. URL: https://assets.kpmg/content/ $\mathrm{dam} / \mathrm{kpmg} / \mathrm{ru} / \mathrm{pdf} / 2021 / 01 / \mathrm{ru}-\mathrm{ru}$-future-of-retail-banking.pdf (дата обращения: 08.12.2021) 
Таблица 2. Ликвидность АО «Тинькофф Банк»*

\begin{tabular}{|c|c|c|c|c|c|c|}
\hline \multirow[t]{2}{*}{ Норматив ликвидности } & \multirow{2}{*}{$\begin{array}{l}\text { Нормативное } \\
\text { значение, уста- } \\
\text { новленное Банком } \\
\text { России,\% }\end{array}$} & \multicolumn{5}{|c|}{ Нормативное значение на отчетную дату,\% } \\
\hline & & На 01.10 .21 & На 01.01 .21 & На 01.01 .20 & На 01.01.19 & На 01.01.18 \\
\hline $\begin{array}{l}\text { Норматив мгновенной } \\
\text { ликвидности банка } \\
\text { (Н2) }\end{array}$ & Минимум 15 & 84.5 & 71.8 & 75.6 & 44.0 & 47.4 \\
\hline $\begin{array}{l}\text { Норматив текущей } \\
\text { ликвидности банка } \\
\text { (H3) }\end{array}$ & Минимум 50 & 131.6 & 125.6 & 144.4 & 127.3 & 156.6 \\
\hline $\begin{array}{l}\text { Норматив долгосроч- } \\
\text { ной ликвидности банка } \\
\text { (H4) }\end{array}$ & Максимум 120 & 26.7 & 18.9 & 20.0 & 15.5 & 5.3 \\
\hline
\end{tabular}

* Отчеты АО «Тинькофф банк» за 2018-2021 гг.

https://acdn.tinkoff.ru/static/documents/a3a6f358-9965-4da4-8b3b-7d5115c696f2.pdf?_ ga=2.241235650.1733481017.1639415470-2045530256.1634458024\&_gac=1.217955556.1638700962.Cj0KCQiA47GN BhDrARIsAKfZ2rBiuDneD2L1uqShad1ZzyBCUiIThvONcUgHgyphejvORkpLiwLnTKQaAsnGEALw_wcB

чем у конкурента, но положение в разрезе долгосрочной ликвидности лучше [5].

Важнейшим для рассмотрения является отчет о прибылях и убытках компаниях, указанный на рисунке 5 .

Необходимо отметить, что компания достаточно динамично наращивает капитал и обязательства, что позволило компании в 2020 году войти в список системно значимых банков. Обязательства компании на 30.09.2021 выросли относительно 2019 года на 93\%. Конечно, доли компаний несравнимы, ПАО «Сбербанк» обладает наибольшей долей на рынке, следовательно, у него в разы больше обязательств и капитала. В период пандемии только банки, выбранные нами для исследования, смогли не только сохранить свои позиции на рынке, но и улучшить их. ЦБ внес АО «Тинькофф Банк» в список системно значимых из-за активного роста бизнеса, который сильно превышает среднерыночный [6].

В результате анализа отчета о движении денежных средств, был сделан вывод, что поток чистых денежных средств, полученных от операционной деятельности, сократился в 4 раза. Так- же компания получила увеличение денежного потока, полученного от финансовой деятельности, за счет бессрочного субсидированного займа в размере 45 млрд. руб.

Далее был проанализирован отчет о финансовых результатах *, который показал, что:

- За 9 месяцев 2021 года компания заработала 46,781 млрд. руб., это на $11 \%$ больше, чем за весь 2020 год - 42,066 млрд. руб., динамика роста прибыли была достаточно низкой, но это не помешало компании сильно увеличить прибыль в 2021 году, с 42,066 млрд. руб. в 2020, и соответственно 41,263 млрд. руб. в 2019. Компания постоянно увеличивает свою прибыль за счет привлечения новых клиентов и грамотного маркетинга. Руководство компании подтверждает прогноз на 2021 финансовый год, основываясь на постепенном восстановлении экономической активности и на положительную динамику качества активов компании. Если прогноз подтвердится, то чистая прибыль составит не менее 60 млрд. руб., это на 43\% больше, чем прибыль за предыдущий период;

- Также были проанализированы опера-

\footnotetext{
*https://acdn.tinkoff.ru/static/documents/8f08df10-12e5-4ada-8712-79e7055971f8.pdf?_ ga $=2.100067422 .1506019116 .1639415738-933240722.1639305120$ https://acdn.tinkoff.ru/static/documents/788b62c6-64e0-405b-ad4f-e2e6fbe202dd.pdf? ga $=2.100067422 .1506019116 .1639415738-933240722.1639305120$ https://acdn.tinkoff.ru/static/documents/0a10969e-abaf-463c-badd-afcbcdf49cdf.pdf? ga=2.100067422.1506019116.1639415738-933240722.1639305120 https://acdn.tinkoff.ru/static/documents/b3ce7d41-2098-4952-b6f9-b380628dd6f3.pdf?_ ga $=2.100067422 .1506019116 .1639415738-933240722.1639305120$
} 


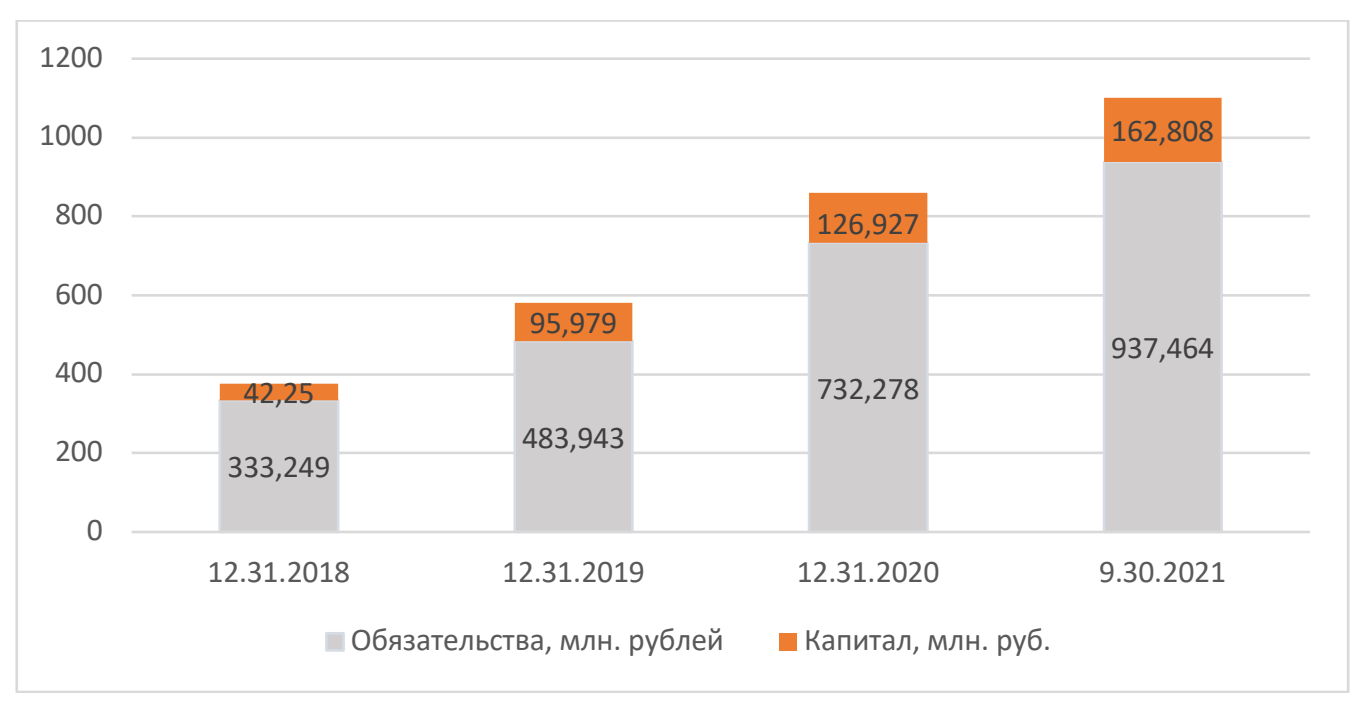

Puc. 5. Капитал и обязательства компании «Тинькофф Банк» (составлено автором на основании источников)

https://acdn.tinkoff.ru/static/documents/1b20a1a8-ab39-4a74-8363-e0ba909ad30d.pdf? $\mathrm{ga}=2.2117104 .1733481017 .1639415470-2045530256.1634458024 \& \_g a c=1.148280517 .1638700962 . C j 0 K C Q i A 47 G N B h$ DrARIsAKfZ2rBiuDneD2L1uqShad1ZzyBCUiIThvONcUgHgyphejvORkpLiwLnTKQaAsnGEALw_wcB https://acdn.tinkoff.ru/static/documents/b025f53b-3f88-4702-872b-94e2b87dbf93.pdf?. $\mathrm{ga}=2.241235650 .1733481017 .1639415470-2045530256.1634458024 \&$ _gac $=1.217955556 .1638700962$. .Cj0KCQiA47GN BhDrARIsAKfZ2rBiuDneD2L1uqShad1ZzyBCUiIThvONcUgHgyphejvORkpLiwLnTKQaAsnGEALw_wcB https://acdn.tinkoff.ru/static/documents/cb8fdb6e-2bfb-4aa0-8b65-6433784ab8ed.pdf?. $\mathrm{ga}=2.241235650 .1733481017 .1639415470-2045530256.1634458024 \&$ _gac $=1.217955556 .1638700962$. .Cj0KCQiA47GN BhDrARIsAKfZ2rBiuDneD2L1uqShad1ZzyBCUiIThvONcUgHgyphejvORkpLiwLnTKQaAsnGEALw_wcB https://acdn.tinkoff.ru/static/documents/f04ebf1d-d376-4984-9e9d-0b901412e5f9.pdf?. $\mathrm{ga}=2.241235650 .1733481017 .1639415470-2045530256.1634458024 \&$ gac $=1.217955556 .1638700962 . C j 0 K C Q i A 47 G N$ BhDrARIsAKfZ2rBiuDneD2L1uqShad1ZzyBCUiIThvONcUgHgyphejvORkpLiwLnTKQaAsnGEALw_wcB

ционные расходы, они увеличились на $70 \%$, это произошло из-за активных инвестиций в маркетинговые кампании и рекламу новых направлений деятельности, также это обусловлено активным ростом клиентской базы, что позволило занять 14,5\% рынка, хотя годом ранее было на $1,5 \%$ ниже.

Для дальнейшего анализа было принято решение проанализировать мультипликаторы. Были рассмотрены показатели рентабельности, чтобы показать динамику изменения финансовой отчетности компаний [7].

Показатель ROA определяет прибыльность компании в зависимости от ее активов, этот расчет позволяет оценить эффективность деятельности руководства компании, положительная динамика показывает на улучшение позиции компании. После анализа мы видим, что ROA у обеих компаний растет, и показатель у АО «Тинькофф Банк» почти в два раза больше.

Важно понимать различие между ROE и ROA, долги компании являются основной разницей, если компания пользуется кредитами и долгами, то рентабельность ее собственного капитала превысит рентабельность активов [8]. ROE у компаний тоже растет, что хорошо отражает их устойчивую позицию на рынке [9].

ROS показывает, сколько компания получает прибыли на вложенные в оборот денежные средства. Данный показатель тоже растет, это означает, что компания эффективно работает.

У компаний произошло небольшое снижение показателей в 2020 году, но сейчас они или почти догнали позиции, которые были раньше, или приближаются к ним [10]. Это показано в Таблице 3 и 4.

Сегодняшнее время можно назвать переломным периодом в развитии банковских услуг [11]. Банкам приходится строить свою деятельность учитывая множество новых факторов, которые приобрели новое значение только в пандемию. Банки, которые успешно приспособились к новым условиям, смогут в будущем расти быстрее рынка, увеличивая прибыль от операционной 
деятельности и сокращая расходы [12]. Главные сферы, в которых произошли изменения - это клиенты, технологии и конкуренты.

В настоящее время приоритеты клиентов изменились, для них наиболее важным стало соотношение цены и качества, а не индивидуальный подход к клиентам, как это было раньше [13]. Это отражено на рисунке 6 .

Сейчас на рынке появляются новые виды банков, которые активно развиваются и занимают значительную долю в финансовой сфере [14]. Они стремятся не просто увеличить прибыль, а масштаб своей деятельности, за счет привлечения новых пользователей и клиентов.

По нашему мнению, АО «Тинькофф Банк» можно отнести к необанкам, а ПАО «Сбербанк» к банкам, которые приняли вызов современности и стремятся следовать трендам и улучшить свои услуги в эпоху изменения банковской среды [15].

Также сейчас нужно учитывать экономическую ситуацию, мировая экономика находится в состоянии рецессии, доверие потребителей падает, а оставшиеся клиенты стремятся эф- фективно распределять свои доходы, сокращать число финансовых операций.

Клиентов можно разделить на четыре категории, показанных на рисунке $7^{* * *}$ :

Аналитики KPMG*** выдели следующие факторы, которые нужно учитывать банкам, которые хотят активно развиваться:

1. Максимально учитывать желания клиентов;

2. Применять agile-подход;

3. Повышать устойчивость;

4. Обеспечивать реалистичный опыт своим клиентам;

5. Использовать новые технологии.

Кризис COVID-19 стал потрясением для всего мира, для России в том числе, но российский кредитный рынок справился с ним лучше, чем с кризисами в период 2008-2009 годов или 2013-2014 годов, благодаря не только грамотной государственной поддержке, но и дисциплине крупнейших, системно-значимых банков РФ. Также в 2020 году ЦБ впервые снизил весовые коэффициенты риска. Именно по этим причинам сейчас банковская среда в России требует

* Отчет KPMG «Будущее Розничных банковских услуг» [Электронный ресурс]. URL: https://assets.kpmg/content/ dam/kpmg/ru/pdf/2021/01/ru-ru-future-of-retail-banking.pdf (дата обращения: 08.12.2021)

** Отчет KPMG «Будущее Розничных банковских услуг» [Электронный ресурс]. URL: https://assets.kpmg/ content/dam/kpmg/ru/pdf/2021/01/ru-ru-future-of-retail-banking.pdf (дата обращения: 08.12.2021)

*** Отчет KPMG «Будущее Розничных банковских услуг» [Электронный ресурс]. URL: https:/assets.kpmg/ content/dam/kpmg/ru/pdf/2021/01/ru-ru-future-of-retail-banking.pdf (дата обращения: 08.12.2021)

Таблица 3. Мультипликаторы ПАО «Сбербанк России»

\begin{tabular}{|c|c|c|c|c|}
\hline Отчетный период & 2018 & 2019 & 2020 & 3 кв. 2021 \\
\hline $\mathrm{ROA}=\frac{\text { Чистая прибыль }}{\text { Активы }}$ & $2,9 \%$ & $2,8 \%$ & $2,3 \%$ & $3,6 \%$ \\
\hline $\mathrm{ROE}=\frac{\text { Чистая прибыль }}{\text { Собственный капитал }}$ & $24,2 \%$ & $21,9 \%$ & $17,0 \%$ & $26,8 \%$ \\
$\mathrm{ROS}=\frac{\text { Чистая прибыль }}{\text { Выручка }}$ & $45,3 \%$ & $44,2 \%$ & $35,2 \%$ & $44,0 \%$ \\
\hline
\end{tabular}

Таблица 4. Мультипликаторы АО «Тинькофф Банк»

\begin{tabular}{|c|c|c|c|c|}
\hline Отчетный период & 2018 & 2019 & 2020 & 3 кв. 2021 \\
\hline ROA & $8,4 \%$ & $7,6 \%$ & $6,2 \%$ & $6,4 \%$ \\
\hline ROE & $64,7 \%$ & $55,9 \%$ & $40,6 \%$ & $42,6 \%$ \\
\hline ROS & $35,5 \%$ & $32,7 \%$ & $33,4 \%$ & $42,2 \%$ \\
\hline
\end{tabular}




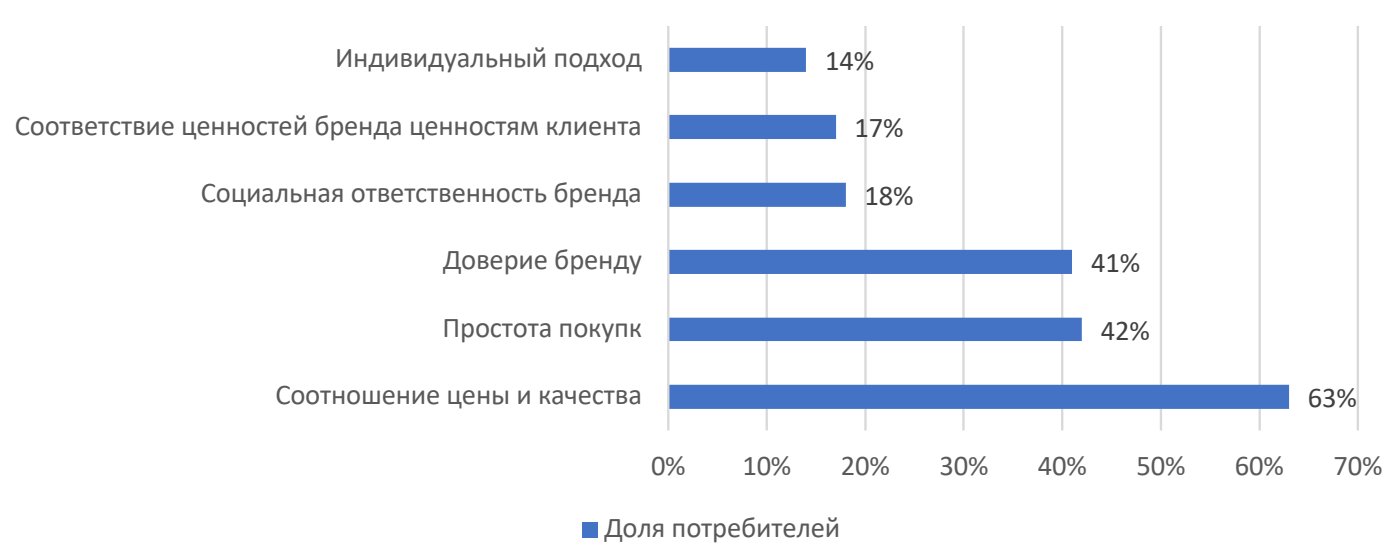

Puc. 6. Главные критерии для потребителя

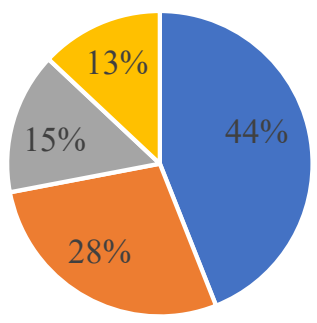

\author{
- Не испытывающие \\ финансовых трудностей \\ - Испытывающие серьезные \\ финансовые трудности \\ - Финансово уязвимые \\ - Уверенные в финансовом \\ отношении
}

Рuc. 7. Разделение клиентов по положению

быстрых и качественных изменений, следование тенденциям позволит увеличивать активно увеличивать клиентскую базу и прибыль, как это делают анализируемые компании. Они смогли быстро приспособиться и изменить привычный тип работы, чтобы быть лидерами на рынке и завоевать новую долю в финансовом секторе. Некоторые показатели снизились из-за пандемии, но правильная траектория развития компаний позволила им увеличить доли на рынке и к концу 2021 года почти нивелировать те ухудшения, которые им пришлось претерпеть.

Выявлены основные факторы, которые позволили компаниям оставаться успешными в сложный период, хотя банковский сектор является цикличным и его положение должно было сильно ухудшиться в период пандемии:

1. Они вели бизнес гибко, выполняли все ожидания клиентов;
2. Создавали интеллектуальные и гибкие услуги;

3. Уделяли время корпоративной культуре, основанной на глубокой ориентированности на клиента;

4. Обеспечивали безупречный клиентский опыт;

5. Много средств тратили на маркетинговые кампании, которые позволяли привлекать новых клиентов, когда другие банки не могли справляться с их запросами.

Ключевыми драйверами роста изучаемых компаний стали такие сферы:

- Банковский бизнес;

- Платежный бизнес;

- Рисковое страхование;

- Управление благосостоянием и брокерские услуги.

Грамотная диверсификация активов повы- 
шает устойчивость банковского бизнеса в период пандемии. Активное развитие новых секторов бизнеса позволяет расширять сферу влияния на новые рынки и конкурировать с банками, умеющими большую долю в сфере кредитования физических лиц. В будущем будет более заметен отрыв тех компаний, которые максимально ориентированы на своих клиентов, на их опыт вза- имодействия с банком. Быть успешным в банковской сфере сейчас - это не просто внедрять новые технологии, это уметь показать клиентам ценность инноваций конкретно для них. Будущее заключается в интегрированных банках, способных поставить в приоритет высочайший уровень клиентского опыта.

\section{Библиографический список}

1. Закон Российской Федерации «О бухгалтерском учете» от 06.12.2011 № 402 // Российская газета. Ст. 15,20,26

2. Указание Банка России от 31.05.2019 N 5158-У «Об обязательных резервных требованиях» [Электронный pecypc]. URL: http://www.consultant.ru/document/cons_doc_LAW_325827/ (дата обращения 11.12.2021).

3. Федеральный закон от 02.12.1990 N 395-1 (ред. от 02.07.2021) «О банках и банковской деятельности» (с изм. и доп., вступ. в силу с 01.09.2021) [Электронный ресурс]. URL: http://www.consultant.ru/document/cons_doc_ LAW_5842/ (дата обращения 11.12.2021).

4. «Гражданский кодекс Российской Федерации (часть первая)» от 30.11.1994 N 51-Ф3 (ред. от 28.06.2021, с изм. от 08.07.2021) [Электронный ресурс]. URL: http://www.consultant.ru/document/cons_doc_LAW_5142/ (дата обращения 11.12.2021).

5. Чернещов С. А. Деньги, кредит, банки: учеб. пособие / Чернещов С. А. - М.: Магистр, 2019. - 494 с. - ISBN 978-5-9776-0108-5. - Текст: электронный. - URL: https://znanium.com/catalog/product/929635 (дата обращения: 14.12.2021). - Режим доступа: по подписке. https://znanium.com/catalog/document?pid=929635

6. Банковские операции: учебное пособие / Лаврушин О.И., под ред., Валенцева Н.И., Ларионова И.В., Мамонова И.Д., Московская Н.А., Ольхова Р. Г., Соколинская Н.Э. - Москва: КноРус, 2021. - 379 с. - ISBN 978-5-406-07874-7. - URL: https://book.ru/book/938243 (дата обращения: 14.12.2021).- Текст: электронный.

7. Финансы и кредит: учебник / под ред. О.В.Соколовой. - 2-е изд., перераб. и доп. - Москва: Магистр: ИНФРА-M, 2020. - 912 с. - ISBN 978-5-9776-0196-2. - Текст: электронный. - URL: https://znanium.com/ catalog/product/1044526 (дата обращения: 05.09.2021). - Режим доступа: по подписке. http://dspace.bsu.edu. ru/bitstream/123456789/27725/1/Rudenko_Sistema_17\%20\%281\%29.pdf

8. Аганбегян А.Г. Финансы, бюджет и банки в новой России / А.Г.Аганбегян. - Москва: Издательский дом «Дело» РАНХиГС, 2019. - 400 с. - ISBN 978-5-7749-1277-3. - Текст: электронный. - URL: https://znanium. com/catalog/product/1043292 (дата обращения: 14.12.2021). - Режим доступа: по подписке. https://znanium. com/catalog/document?pid=1043292

9. Горловой Д.Н., Мазий В.В. Банковские инновации: перспективы и проблемы внедрения // Вестник Евразийской науки, 2020 № 1, https://esj.today/PDF/65ECVN120.pdf (доступ свободный). Загл. с экрана. Яз. рус., англ.

10. Балюк И.А. Тенденции развития международного рынка долговых ценных бумаг // Финансы: Теория и Практика - 2017 - С. 69-8.

11. Дицуленко О.И., Посная Е. А., Черемисинова Д.В. // Финансовые исследования Финансовые исследования оㅡㄴ 1(66) 2020 г., С. 34.

12. Рудская Е.Н. Банковская сфера как цифровая экосистема: проблемы и тенденции //-Economy and Business $2019 / /$

13. С.А. Зубов Кредитование физических лиц в январе-апреле 2021 г.: рост показателя долговой нагрузки // Экономическое развитие России 2021 C. 36 https://cyberleninka.ru/article/n/kreditovanie-fizicheskih-lits-vyanvare-aprele-2021-g-rost-pokazatelya-dolgovoy-nagruzki.

14. Милославская Н.А. Сложные вопросы учета собственного капитала [Электронный ресурс]: - Режим доступа: https://znanium.com/read?id=374181

15. Таштамиров М.Р., Мазаева Л.В., Куриев 3.Д. Ретроспективный анализ обеспеченности регионов банковскими услугами // Вестник Евразийской науки, 2019 № 5, https://esj.today/PDF/35ECVN519.pdf (доступ свободный). Загл. с экрана. Яз. рус., англ. 